Научная статья

УДК 331.5

DOI 10.18101/2304-4446-2020-4-10-17

\title{
СОВРЕМЕННЫЕ ТЕНДЕНЦИИ РЫНКА ТРУДА И ПРОБЛЕМЫ ПРОДВИЖЕНИЯ СПЕЦИАЛИСТОВ В УСЛОВИЯХ РОСТА БЕЗРАБОТИЦЫ
}

\author{
(C) Афонасова Маргарита Алексеевна \\ доктор экономических наук, профессор, \\ Томский государственный университет систем управления и радиоэлектроники \\ Россия, 634050, г. Томск, пр. Ленина, 40 \\ afonasova@yandex.ru
}

\begin{abstract}
Аннотация. В статье анализируется ситуация на российском рынке труда в условиях экономического кризиса, вызванного пандемией коронавируса и падением цен на энергоносители, рассматриваются требования современного рынка труда к профессиональным и личностным качествам специалистов. Акцентируется внимание на инструментах самомаркетинга как важной коммуникативной технологии, используемой на рынке труда в конкурентной среде. Обосновывается тезис о необходимости приобретения работниками дополнительных компетенций в условиях широкого распространения альтернативных форм трудоустройства. В статье рассмотрены вопросы регулирования рынка труда, а также основные меры государственной поддержки наиболее пострадавших отраслей, в том числе меры, направленные на поддержание занятости. Проведен анализ данных федеральной службы государственной статистики, отражающий наличие проблем на российском рынке труда.

Ключевые слова: рынок труда; занятость; безработица; специалисты; конкурентоспособность; коммуникативные технологии.
\end{abstract}

\section{Для цитирования}

Афонасова М. А. Современные тенденции рынка труда и проблемы продвижения специалистов в условиях роста безработицы // Вестник Бурятского государственного университета. Экономика и менеджмент. 2020. № 4. С. 10-17.

В настоящее время ситуация на российском рынке труда многими экспертами идентифицируется как критическая. Мировой энергетический кризис, пандемия коронавируса, сжатие экономического пространства значительно повлияли на сокращение масштабов экономической деятельности в стране. Плюс условия российского рынка труда: «наша экономика не генерирует рабочие места, мы уже больше 20 лет видим отрицательное сальдо между созданными и сокращенными рабочими местами. Еще один важный момент - проведение в 2018 г. пенсионной реформы и появление дополнительной рабочей силы» [1], которая также усугубляет проблему занятости населения, поиска высокооплачиваемых рабочих мест, соответствующих уровню подготовки и компетенциям работников.

По данным Росстата, уровень безработицы в РФ в апреле 2020 г. составил $5,8 \%$ (рис. 1$)^{1}$. При этом уровень безработицы среди сельских жителей превыша-

\footnotetext{
1 Занятость и безработица в Российской Федерации в апреле 2020 г. (по итогам обследования рабочей силы) [Электронный pecypc]. URL: www.gks.ru/free_doc/2020/ b20_01/100.htm (дата обращения: 20.04.2020).
} 
М. А. Афонасова. Современные тенденции рынка труда и проблемы продвижения специалистов в условиях роста безработицы

ет уровень безработицы среди городских жителей (8,0\% против 5,1\%). Уровень безработицы мужчин превышает уровень безработицы женщин $(6,1$ и 5,4\% соответственно) ${ }^{1}$.

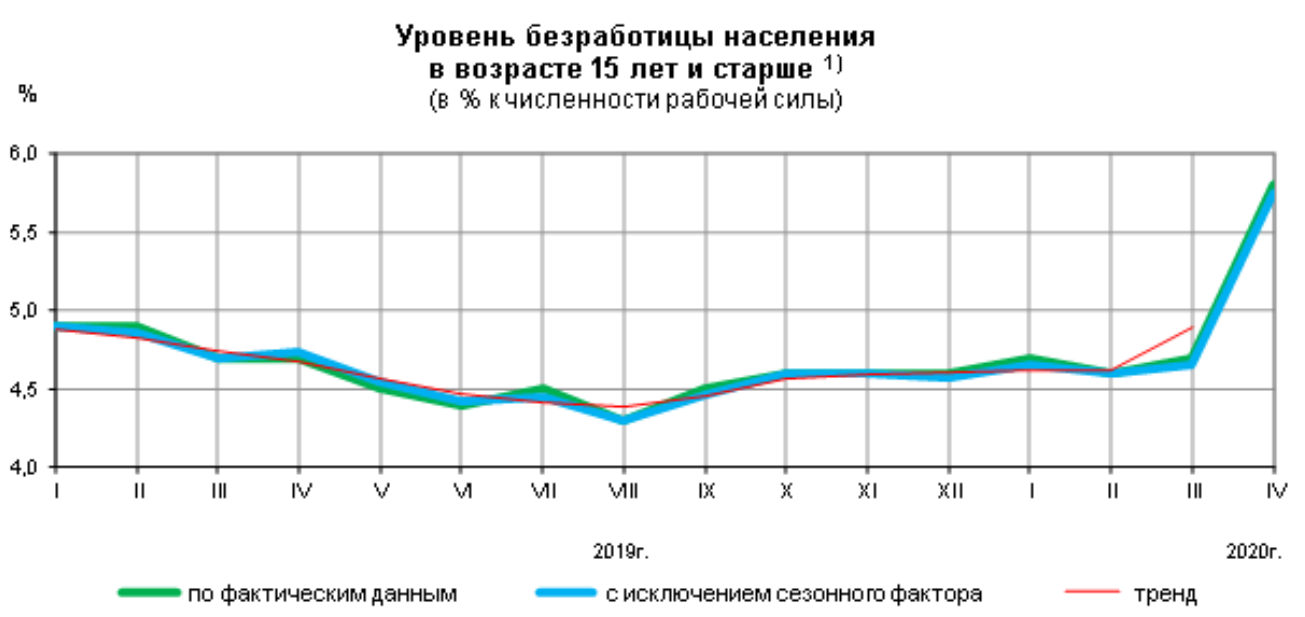

1) Оченка данных с исключением сезонного фактора осуществлена с использованием программы "JDemetra+». При поступлении новых данных статистических наблюдений динамика может быть уточнена.

Рис. 1. Уровень безработицы в РФ (по данным Росстата)

По прогнозу Высшей школы экономики, при базовом сценарии развития событий в экономике уровень безработицы в России в 2020 г. составит $8 \%$, при худшем варианте развития событий он вырастет до 9,5\%, а в 2021 г. - до $9,8 \%{ }^{2}$. То есть ожидаются проблемы на рынке труда. И они уже начались. Падение реальных доходов населения в нынешнем кризисе 2020 г. будет больше зависеть не от инфляции и девальвации рубля, а от снижения объемов малого и среднего бизнеса и роста безработицы.

По мнению экспертов, наша экономика переживает «шок спроса», в результате которого больше всего пострадали секторы, ориентированные на потребительский спрос и экспорт, а также малый и средний бизнес.

В августе 2020 г., спустя почти полгода после начала экономического кризиса, вызванного пандемией коронавируса и падением цен на энергоносители, в России продолжается рост безработицы. По оценкам Росстата, уровень безработицы в августе в РФ составил $6,4 \%$ экономически активного населения ${ }^{3}$. Это худший

\footnotetext{
1 Занятость и безработица в Российской Федерации в апреле 2020 года (по итогам обследования рабочей силы) [Электронный ресурс]. URL: www.gks.ru/free_doc/2020/ b20_01/100.htm s (дата обращения: 20.04.2020).

${ }^{2}$ Минтруд допустил появление до 6 млн безработных в России после эпидемии [Электронный ресурс]. URL: www.rbc.ru/society/28/04/2020/ 5ea87a179a794752f55d0511 (дата обращения: 20.04.2020).

3 Росстат оценил рынок труда в августе [Электронный ресурс]. URL: www.kommersant.ru/doc/4512000 (дата обращения: 20.04.2020).
} 
показатель за последние восемь лет. Причем в эту цифру входят только те, кто официально обратился на биржу труда, а те, кто не зарегистрирован в качестве безработного, но не работает в данный момент, в эту статистику не входят. А таких десятки миллионов человек. Число безработных в августе в РФ было равно 4,8 млн человек. Средний возраст безработных составил 35,6 года, доля молодежи до 25 лет была равна 21,8\%, россиян старше 50 лет - 15,9\%. Из 4,8 млн безработных 1,4 млн составляли сельские жители ${ }^{1}$.

Из 75 млн трудоспособных граждан заняты на полный рабочий день с гарантированной оплатой труда всего 33,3 миллиона человек, или 44,4\% от всей рабочей силы ${ }^{2}$.

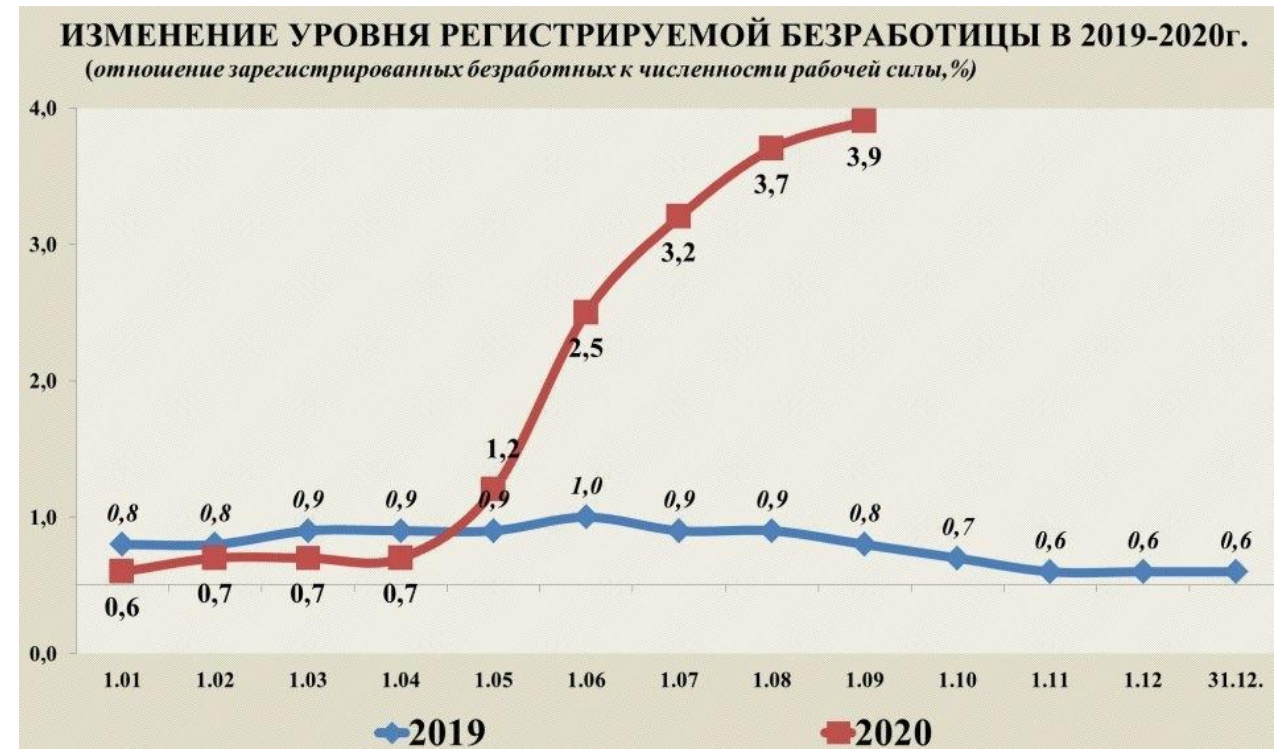

Рис. 2. Динамика регистрируемой безработицы в РФ в 2019-2020 гг. ${ }^{3}$.

Даже по сильно заниженным официальным данным число безработных выросло в 4,5 раза по сравнению с мартом 2020 г. В условиях, когда рынок труда сокращается, а конкуренция за рабочие места растет, работники не стремятся сменить место работы, а для тех, кто ее потерял, поиск достойной работы, соответствующей компетенциям, опыту и профилю соискателя, превращается в сложную, нетривиальную задачу, решать которую приходится, применяя специальные методы и технологии, например такие, как самомаркетинг.

В условиях ужесточения конкуренции на рынке труда самомаркетинг можно рассматривать как важную составляющую часть компетенции специалиста, связанную с умением продвигать себя на рынке труда. Работник в современной

1 Росстат оценил рынок труда в августе [Электронный pecypc]. URL: www.kommersant.ru/doc/4512000 (дата обращения: 20.04.2020).

2 Безработица в РФ выросла в 4,5 раза [Электронный pecypc]. URL: https://zen.yandex.ru/media/burckina_faso/ (дата обращения: 20.04.2020).

Там же. 
М. А. Афонасова. Современные тенденции рынка труда и проблемы продвижения специалистов в условиях роста безработицы

конкурентной среде должен стремиться занимать выгодное положение на рынке, проявлять инициативу, используя свои природные данные, приобретенные знания и навыки, демонстрируя при этом активную жизненную позицию.

Самомаркетинг связан с умением формировать положительный профессиональный имидж, продвигать свой персональный бренд. Он необходим как в ситуации поиска работы, так и для развития собственной профессиональной карьеры. По мнению известного эксперта и авторитета в области маркетинга Я. Филлипсона, самомаркетинг - это систематическое повышение рыночной стоимости самого себя. Он помогает успешно найти работу и ускорить продвижение по служебной лестнице [2].

Поскольку любой специалист - это товар на рынке труда, а рынок труда представляет собой конкурентный рынок, то самомаркетинг можно рассматривать как важную коммуникативную технологию как на этапе трудоустройства, так и в период кадровых перемещений, карьерного роста, ротации персонала. Чаще всего его рассматривают как комплекс действий, связанных с собственным продвижением на рынке труда, повышением своей рыночной стоимости [3].

Специалисты говорят, что существует большое количество людей, которые обладают врожденными природными способностями к самомаркетингу. Это люди, которые обычно нравятся потенциальным работодателям, так как умеют демонстрировать свои лучшие качества, прекрасно чувствуют профессиональную конъюнктуру, обладают навыками самопрезентации [2].

Однако, как показывает опыт, зачастую работники, филигранно владеющие навыками самопрезентации, оказываются далеко не лучшими специалистами в своей профессиональной области. Эксперты считают, что любой работник, имеющий опыт в своей профессиональной сфере, в состоянии овладеть необходимыми навыками самомаркетинга, чтобы успешно конкурировать на рынке труда. В настоящее время существует множество различных приемов самомаркетинга, на освоение которых не требуется много усилий и времени. А вот грамотное использование этих приемов при поиске работы может быть очень полезным в условиях высокой конкуренции на рынке труда.

Самомаркетинг работника, претендующего на повышение по службе, в зарплате и т. д., проявляется через демонстрацию своих компетенций, знаний, потенциальных возможностей и навыков. Нужно показать работодателю лучшие черты своего характера, кругозор, совокупность взглядов, а также упомянуть о некоторых своих недостатках. Адекватная самооценка человека обычно положительно оценивается работодателем.

Самомаркетинг предполагает также совершенствование человеком своего имиджа. Здесь важны внешние атрибуты имиджа человека: одежда, манера держаться, жесты и т. п., которые играют не менее важную роль при формировании первого впечатления в процессе приема на работу, чем образование и уровень знаний специалиста. Кроме того, внешний вид человека важен и для ощущения уверенности в себе, для повышения самооценки. Перемены в жизни и карьере обычно следуют за сменой внешнего облика человека.

Однако следует учесть, что современный работодатель учитывает не только внешний вид, коммуникативные навыки и уверенность человека в себе. Все-таки в первую очередь он делает ставку на профессиональные качества, навыки и по- 
тенциал специалиста. Поэтому главная составляющая «продукта» на рынке труда - это профессиональные компетенции человека, претендующего на конкретную должность. Здесь важными составляющими являются практический опыт работника, накопленные им знания и умения. Следовательно, наиболее важным фактором конкурентоспособности работников на рынке труда является их профессиональный опыт, а также практические навыки, приобретенные в течение трудовой деятельности. Также ценятся дополнительные компетенции работников, такие как владение информационными технологиями, английским языком, готовность к командировкам и т. п. Но эти факторы конкурентоспособности работников не отменяют необходимость владения и применения технологий самопродвижения, самомаркетинга, тем более в условиях падающей экономики, роста напряженности на рынке труда.

В результате опроса более 150-ти работодателей, проведенного крупнейшей российской компанией в сфере интернет-услуг по поиску работы «HeadHunter», было выяснено, что в 2020 г. каждая десятая компания планирует сократить персонал вследствие неблагоприятной финансово-экономической ситуации и общего падения доходности бизнеса [4].

В условиях введения ограничительных мер и падения деловой активности бизнес во всем мире терпит значительные убытки. Данная проблема коснулась большинства отраслей экономики, в особенности субъектов малого и среднего предпринимательства. Поэтому важное значение в этих условиях приобретают меры поддержки государства наиболее пострадавших отраслей, в том числе меры, направленные на поддержание занятости.

На наш взгляд, важнейшей сферой, требующей поддержки со стороны государства, является работа для молодёжи, выпускников вузов и учреждений среднего профессионального образования. По разным оценкам, на рынок труда летом 2020 г. вышло более 1,5 млн выпускников высших и средних учебных заведений, которым сложно трудоустроиться в этой непростой ситуации, ведь работодатели больше ценят опыт и профессиональные навыки, чем только что полученный диплом. Выпускников вузов и колледжей работодатели недолюбливают за низкий уровень ответственности, отсутствие самоорганизации и дисциплины, а также высокие зарплатные ожидания. Учитывая растущее количество кандидатов на рынке труда и уровень конкуренции, работодатели предпочитают принимать на работу специалистов с опытом работы от 3-5 лет, уже прошедших «первичную обработку» в других компаниях и получивших начальный опыт. Конкуренция на рынке труда в настоящее время стала ещё более жёсткой, что может существенно снизить шансы молодежи на трудоустройство. Вот здесь впервые ищущим работу молодым людям потребуются навыки самомаркетинга, приобретенные в учебных заведениях.

Одной из мер, направленных на поддержание занятости в условиях пандемии, стало создание временных рабочих мест, на что Правительством РФ выделено регионам более 4 млрд р. Временные рабочие места создаются в сферах строительства, агропромышленного комплекса, транспорта, ЖКХ, благоустройства [4]. Еще одной мерой является перевод сотрудников на неполную занятость.

Чтобы реально улучшить положение дел с занятостью, надо, во-первых, сделать важнейшим государственным приоритетом создание новых рабочих мест в 
М. А. Афонасова. Современные тенденции рынка труда и проблемы продвижения специалистов в условиях роста безработицы

промышленности, агропромышленном секторе, строить новые предприятия, фабрики, заводы, оснащенные новыми технологиями, а также активнее применять новые методы в сфере трудоустройства. Специалисты портала «Работа.ру» после опроса 6700 пользователей сервиса во всех регионах России пришли к выводу, что $72 \%$ российских компаний пока не смогли полностью восстановиться после карантина, а количество россиян, полностью перешедших в компаниях на удаленный режим работы с конца марта 2020 г., выросло почти в пять раз ${ }^{1}$. Такая форма стала удобной для многих категорий работников, прежде всего для тех, у кого есть ограничения по здоровью или маленькие дети. Удаленная работа является привлекательной для таких сфер занятости, как информационные технологии, онлайн-ритейл, ряд программ дополнительного образования для взрослых, программ повышения квалификации и т. п.

Таким образом, можно выделить следующие основные тренды на рынке труда в 2020 г.:

- работодатели становятся все более требовательными к кандидатам на вакантные должности, к их компетенциям и опыту работы;

- рынок труда все более становится рынком работодателей (если раньше на одного соискателя приходилось 4-5 вакансий, то сейчас на 1 вакансию претендуют 4-5 кандидатов);

- работникам приходится снижать уровень своих притязаний и отказываться от стратегии поиска «лучшей работы»;

- набирают популярность альтернативные формы трудоустройства, такие как онлайн, фриланс, неполный рабочий день, самозанятость;

- растет конкуренция между онлайн- и офлайн-занятостью;

- наблюдается запрос со стороны безработных граждан на создание собственного дела.

В заключение отметим, что жесткие условия конкуренции на рынке труда требуют от работников постоянного повышения уровня квалификации, получения опыта не только в профессиональной области, но и в сфере самомаркетинга, который в настоящее время является важной составляющей компетентности работника, оказывающей влияние на его карьерные перспективы и повышение конкурентоспособности на современном рынке труда. В условиях действующих ограничений, вызванных пандемией коронавируса, с самыми большими трудностями на рынке труда, как показывает практика, столкнулись линейные специалисты без высокой квалификации, доля вакансий для которых резко сократилась, и выпускники вузов, не имеющие опыта практической деятельности. На этом фоне на рынке труда растет спрос на могофункциональных специалистов, так называемых специалистов «полного цикла», которые сами и стратегию могут разработать, и план составить, и сами его выполнят, и новую мотивацию себе сформируют. В зоне наибольшего риска оказалось несколько социальных групп: возрастные сотрудники, молодые специалисты (выпускники вузов и ссузов) и женщины, планирующие выход из декрета. Все эти группы с точки зрения рабо-

\footnotetext{
${ }^{1}$ Опрос: большинство российских компаний полностью не восстановились после карантина [Электронный ресурс]. URL: https://tass.ru/ekonomika/9576505 (дата обращения: 20.04.2020).
} 
тодателей - проблемные, с ними связаны дополнительные риски, затраты и высокие социальные обязательства ${ }^{1}$.

Подводя итог, можно сказать, что общая ситуация в сфере занятости остаётся напряжённой. Основное проблемное поле наблюдается при сопоставлении структуры безработицы и имеющегося банка вакансий. Здесь наблюдается несоответствие навыков безработных граждан востребованным работодателями компетенциям, а также разница в зарплатных ожиданиях и реальном денежном предложении (работодатели предлагают уровень оплаты труда на $15-25 \%$ меньше, чем хотели бы получать работники). Для помощи в трудоустройстве молодых специалистов создана так называемая цифровая витрина стажировок и практик на базе портала «Работа в России». Также на этом портале создаются специальные цифровые платформы, дающие возможность человеку в зависимости от региона или профессии быстрее найти работу. В регионах действуют программы трудоустройства лучших выпускников вузов в академическом секторе и в университетах, а также программы субсидирования рабочих мест в высокотехнологичном секторе. Все эти меры направлены на то, чтобы удержать человеческий капитал в регионах и в стране, на который будет опираться наше общество, обеспечивая следующий шаг в экономическом развитии.

\section{Литература}

1. Прокофьев А. Безработица и коронавирус: что происходит на рынке труда [Электронный ресурc]. URL: https:// polit.ru/article/2020/05/06/ coronaworkfail/utm_source= yxnews\&utm_medium=desktop\&utm_referrer=https\%3A\%2F\%2Fyandex.ru\%2Fnews (дата обращения: 20.04.2020).

2. Филлипсон Я. Как «продавать» себя. Практическое пособие по самомаркетингу. Челябинск: Урал LTD, 1997. 160 с.

3. Морозова Е. В. Самомаркетинг - искусство продавать себя на рынке труда [Электронный ресурc]. URL: http:// yarpoisk.ru/jobseeker/articles/self-marketing/ (дата обращения: 20.04.2020).

4. Бондаренко Н. Е. Российский рынок труда в условиях пандемии коронавирусной инфекции: тенденции, вызовы и государственное регулирование // Инновации и инвестиции. 2020. № 7. С. 63-69 [Электронный ресурс]. URL: https://cyberleninka.ru/article/n/ rossiyskiy-rynok-truda-v-usloviyah-pandemii-novoy-koronavirusnoy-infektsii-tendentsiivyzovy-i-gosudarstvennoe-regulirovanie (дата обращения: 20.04.2020).

1 Каким будет рынок труда к концу 2020 г. [Электронный pecypc]. URL: www.klerk.ru/buh/articles/503427/ (дата обращения: 20.04.2020). 


\title{
MODERN TRENDS OF LABOUR MARKET AND PROBLEMS \\ OF PROFESSIONAL ADVANCEMENT IN THE CONDITIONS OF GROWING UNEMPLOYMENT
}

\author{
Margarita A. Afonasova \\ Dr. Sci. (Econ.), Prof., \\ Tomsk State University of Control Systems and Radioelectronics \\ 40 Lenina Prospect, Tomsk 634050, Russia \\ afonasova@yandex.ru
} Abstract. The article analyzes the labour market situation in Russia in the face of the eco-
nomic crisis caused by the coronavirus pandemic and the fall in energy prices. We consider
the requirements of the modern labour market for competency and personal qualities of pro-
fessionals. The attention is focused on self-marketing tools as an important communication
technology used in a competitive environment of labour market. We have rested argument
on the need for employees to acquire additional competencies in the spread of alternative
forms of employment. The article discusses the issues of labour market regulations, as well
as the main measures of government support for the most affected industries, including
measures aimed at maintaining employment. An analysis of the data from the Federal State
Statistics Service have shown the current problems in the Russian labour market.
Keywords: labour market; employment; unemployment; professionals; competitiveness;
communication technologies.

Статья поступила в редакцию 07.10.2020; одобрена после рецензирования 30.10.2020; принята к публикации 30.10.2020. 